\title{
Rancang Bangun Aplikasi Penelusuran Kehilangan Perangkat Mobile Berbasis Android
}

\author{
Indra Suwahyono \\ Program Studi Sistem Komputer Fakultas Teknik Universitas Diponegoro \\ Jalan Prof. Sudharto, Tembalang, Semarang, Indonesia \\ soewahyono@gmail.com
}

\begin{abstract}
In this modern era, android based smart phone widely dominate the world market, especially Indonesia. Not only possessed by the premium class it also used by middle and lower class customer, though sometimes prone to be lost or misplaced somewhere. This study purposed to develop an application that is able to trace the missing android smart phone in order to avoid loss or being hidden unintentionally that possibly put the owner into a very difficult situation, especially if the smart phone or mobile device has moved away from the known missing position.

Lost mobile device tracking application, used to trace and discover the position of a lost smart phone. It built using the Java programming language in the Eclipse IDE and the Android SDK software. It also designed using waterfall method, a method that shows a systematic and sequential approach through stages in SDLC (Software Development Life Cycle) and software modeled using UML (Unified Modeling Language). The application active and works by using SMS commands and sent to a friend's phone number that already registered. SMS command 'siren' to ring the alarm, as well as SMS command 'where' to know the latitude and longitude coordinates using GPS assistance to get the map location and Google Maps API to get the route to the location.

The entire available features menu in the lost mobile device tracking application has been tested and running normally. Work using SMS commands that ease the users to run the application as long as credits balance available. For further development, this application is expected to control the system remotely so the important data protected and cannot be accessed by the inventor.
\end{abstract}

Key Term: Android, Eclipse, Command SMS, GPS, Google Maps API

\section{PENDAHULUAN}

$\mathrm{P}$ ERANGKAT mobile atau smartphone android umumnya memiliki beberapa spesifikasi hardware yang digunakan serta harga tinggi jika kualitas spesifikasinya sangat bagus. agar terhindar dari kehilangan maupun tangan jahil yang menyembunyikan smartphone tersebut, sebagai pemilik akan sulit untuk menemukannya, terlebih lagi jika smartphone atau perangkat mobile sudah berpindah tempat yang jauh dari posisi saat smartphone hilang. Agar dapat mengamankan dan menemukan smartphone yang hilang ataupun lupa menaruhnya, dengan memanfaatkan perintah SMS, yang akan membunyikan suara alarm, serta menampilkan koordinat yang memanfaatkan GPS untuk mendapatkan peta dan Google Maps APIs agar bisa menampilkan rute.

\section{A. Rumusan Masalah}

Berdasarkan latar belakang masalah tersebut, dapat dibuat suatu rumusan masalah sebagai berikut.
"Bagaimana merancang bangun aplikasi yang mampu menyampaikan petunjuk saat kehilangan perangkat mobile android, dengan memberikan informasi berupa bunyi alarm, serta koordinat lintang dan koordinat bujur pada GPS?".

\section{B. Batasan Masalah}

Untuk menghindari pembahasan yang meluas, maka dalam penulisan tugas akhir ini ditetapkan batasan-batasan masalah sebagai berikut:

1. Aplikasi menggunakan perangkat lunak Eclipse IDE dan Android SDK.

2. Aplikasi penelusuran kehilangan dapat berjalan pada saat kondisi smartphone atau perangkat mobile android dalam kondisi hidup, serta koneksi internet untuk mengakses GPS, Google Maps API dan membutuhkan pulsa simcard.

3. Aplikasi tidak menggunakan database, dan dirancang untuk berjalan pada sistem operasi android minimal versi ginger bread (2.3.3) sampai jelly bean (4.1.2).

4. Pengujian aplikasi penelusuran kehilangan perangkat mobile, harus menyimpan nomor telepon terlebih dahulu, jika nomor telepon tergolong nomor gsm, maka harus menggunakan format internasional yaitu kode negara Republik Indonesia (+628), sedangkan format internasional nomor cdma (088).

5. Kemampuan sinyal dari perangkat mobile atau smartphone, akan mempengaruhi jalan kerjanya aplikasi, yang dimana dalam pengujian untuk menentukan posisi koordinat, jangan dilakukan di sebuah ruangan agar bisa mendapat koordinat dari keluaran GPS, serta ada beberapa smartphone atau perangkat mobile harus menghidupkan GPS terlebih dahulu.

\section{TINJAUAN PUSTAKA}

\section{A. Sistem Operasi Android}

Android adalah sistem operasi untuk telepon seluler yang berbasis Linux. Android menyediakan platform terbuka bagi para pengembang buat menciptakan aplikasi mereka sendiri untuk digunakan oleh bermacam peranti bergerak. Awalnya, Google Inc. membeli Android Inc., pendatang baru yang membuat peranti lunak untuk ponsel. Kemudian untuk mengembangkan Android, dibentuklah Open Handset Alliance, konsorsium dari 34 perusahaan peranti keras, peranti lunak, dan telekomunikasi, termasuk Google, HTC, Intel, Motorola, Qualcomm, T-Mobile, dan Nvidia. ${ }^{[7]}$

\section{B. Eclipse}

Eclipse adalah sebuah software IDE (Integrated Development Environment) open source yang dibuat oleh perusahaan Eclipse Foundation, untuk mengembangkan perangkat lunak juga dapat dijalankan di semua platform. 
Pengembangan terbuka terdiri dari kerangka kerja dan alat runtimes untuk membangun, menyebarkan dan mengelola perangkat lunak diseluruh siklus hidup. ${ }^{[9]}$

\section{C.SDK (Software Development Kit)}

Android SDK itu Tools API (Application Programming Interface) diperlukan untuk mengembangkan aplikasi pada platform Android. Adanya Android SDK sebagai alat bantu dan API untuk memulai mengembangkan aplikasi Android. Di dalam android SDK terdapat debugger, libraries, dan emulator. ${ }^{[3]}$

\section{SMS (Short Message Service), Remote Access, GPS (Global}

Positioning system), Google Maps API

Sistem SMS, mekanisme utama yang dilakukan dalam sistem adalah melakukan pengiriman short message dari satu terminal pelanggan ke terminal yang lain. ${ }^{[2]}$

Remote Access adalah kemampuan untuk mengakses resource-resource pada jaringan komputer sentral dari lokasi manapun. Ini berarti menggunakan PC dan modem di tempat yang jauh untuk berhubungan dengan $\mathrm{PC}$ atau server di jaringan komputer utama perusahaan melalui saluran telepon. ${ }^{[6]}$

GPS mengetahui posisi objek yang diinginkan dengan bantuan perangkat yang memiliki sensor GPS di dalamnya. GPS bekerja ketika sejumlah satelit yang berada di orbit Bumi memancarkan sinyalnya ke Bumi kemudian sinyal tesebut ditangkap oleh sebuah alat penerima yang nantinya diubah menjadi informasi berupa titik lokasi dari alat penerima tersebut. Untuk itu perlu diperhatikan hal yang dapat mengganggu sinyal satelit antara lain, kondisi geogragfis, alat yang menggunakan gelombang elektromagnetik, gedung dan sinyal yang memantul. ${ }^{[9]}$

API (Application Programming interface)merupakan antarmuka atau penghubung antara aplikasi atau web yang kita buat dengan fungsi-fungsi yang dikerjakan. Misalnya dalam hal ini Google API berarti kode program yang dapat ditambahkan pada aplikasi atau web, untuk mengakses, menjalankan dan memanfaatkan fungsi atau fitur yang disediakan oleh Google. ${ }^{[9]}$

\section{E. Pengembangan Perangkat Lunak}

Pengembangan perangkat lunak tidak akan terlepas dari sebuah Software Development Life Cycle (SDLC). Dalam SDLC terdapat beberapa metode yang dapat dipakai untuk mengembangkan sebuah perangkat lunak diantaranya metode waterfall.

Metode Waterfall adalah metode yang menyarankan sebuah pendekatan yang sistematis dan sekuensial melalui tahapantahapan yang ada pada SDLC untuk membangun sebuah perangkat lunak. Metode Waterfall menekankan pada sebuah keterurutan dalam proses pengembangan perangkat lunak. Metode ini adalah sebuah metode yang tepat untuk membangun sebuah perangkat lunak karena dilakukan secara bertahap, sehingga kualitas dari sistem yang dihasilkan akan baik. Akan tetapi jika kesalahan di awal tahap berakibat sangat fatal pada tahap berikutnya. ${ }^{[12]}$

\section{F. Pengujian Black Box}

Pengujian Black Box berfokus pada persyaratan fungsional perangkat lunak. Dengan demikian, pengujian black box memungkinkan perekayasa perangkat lunak mendapatkan serangkaian kondisi input yang sepenuhnya menggunakan semua persyaratan fungsional untuk suatu program. Pengujian black box merupakan pendekatan komplementer yang kemungkinan besar mampu mengungkap kelas kesalahan. Pengujian black box berusaha menemukan kesalahan dalam kategori sebagai berikut, fungsi -fungsi yang tidak benar atau hilang, kesalahan interface, kesalahan dalam struktur data atau akses database eksternal, kesalahan kinerja, inisialisasi dan kesalahan terminasi. ${ }^{[11]}$

\section{PERANCANGAN PENELITIAN \\ A.Perancangan Perangkat Lunak Menggunakan Metode Waterfall}

Metode waterfall adalah metode yang menyarankan sebuah pendekatan sistematis dan sekuensial melalui tahapan-tahapan yang ada pada SDLC untuk membangun sebuah perangkat lunak. Metode ini memberikan pendekatan-pendekatan sistematis dan berurutan bagi pengembangan perangkat lunak.

\section{B. Analisa Kebutuhan}

Mempelajari kebutuhan pengguna sistem sangat penting dilakukan untuk mengetahui akan seperti apa perangkat lunak berjalan nantinya. Seringkali terjadi kesalahan maupun ketidak sepahaman antara aplikasi yang dibuat dengan keinginan dari pengguna aplikasi. Untuk itu diperlukan analisis yang mendasar dan rinci melalui berbagai media referensi terhadap kebutuhan sistem.

\section{Dekripsi Umum}

Aplikasi Penelusuran Kehilangan Perangkat Mobile Berbasis Android, menggunakan bahasa Indonesia, dilengkapi dua perintah SMS yaitu "dimana" untuk mengetahui lokasi koordinat posisi smartphone dan "sirine" untuk membunyikan suara alarm pada smartphone yang sudah terinstall aplikasi ini. Kebutuhan Fungsional

Kebutuhan fungsional merupakan layanan yang harus diberikan oleh sistem. Kebutuhan fungsional berhubungan dengan fitur perangkat lunak yang akan dibuat.

1. Memberikan informasi saat smartphone kembali diaktifkan (reboot), atau smartphone android yang hilang telah mengalami penggantian kartu telepon (simcard).

2. Cara mengetahui posisi letak keberadaan smartphone android, dengan menggunakan kata perintah SMS, yaitu 'sirine' dan 'dimana'.

3. Aplikasi penelusuran kehilangan perangkat mobile, dapat berjalan dengan koneksi internet agar dapat mengakses GPS, Google Maps API, dan membutuhkan pulsa.

4. Visualisasi letak keberadaan dengan koordinat lintang dan kooordinat bujur smartphone berupa aplikasi tambahan seperti, peta digital (google map).

5. Rute atau alur jalannya yang akan dilalui dari posisi nomor telepon teman yang melacak letak keberadaan, ke posisi smatphone yang hilang.

6. Menbunyikan suara alarm pada smartphone yang hilang, dengan fungsi mengetahui secara pasti untuk letak posisi yang terdekat.

\section{Kebutuhan non fungsional}

Kebutuhan non-fungsional merupakan kebutuhan yang tidak berhubungan langsung dengan spesifik yang telah dirancang oleh sistem. Mengenai kebutuhan yang digunakan untuk membuat atau membangun, serta menjalankan program dalam pengembangan aplikasi perangkat lunak dan perangkat keras.

Perangkat Lunak

1. Android SDK, merupakan Tools API (Application Programming Interface) yang diperlukan untuk mengembangkan aplikasi pada platform Android.

2. Eclipse merupakan sebuah IDE (Integrated Development Environment) open source yang bertujuan menghasilkan platform pemrograman terbuka. Eclipse sebagai editor 
bahasa pemrograman java, Android Development Tools (ADT) merupakan plugin untuk Eclipse dan SDK untuk kepentingan development aplikasi berbasis android.

\section{Perangkat Keras}

1. Netbook milik penulis, dengan spesifikasi sistem operasi Microsoft Windows XP Home Edition (5.1 build 2600), Intel® N270 CPU @1.60GHz (2 CPUs), RAM 1016MB, hard disk 1600 GB sebagai piranti pembuatan dan pengembangan aplikasi.

2. Smartphone Samsung galaxy w GT-I8150 dengan spesifikasi sistem operasi android CyanogenMod 4.0.4 (ice cream sandwich), Processor $1.40 \mathrm{GHz}$ Qualcomm Snapdragon MSM8255T, GPU Adreno 205, RAM 0.50GB, ROM 4GB. Digunakan untuk pengujian aplikasi pada smartphone dengan sistem operasi Android.

\section{D.Pemodelan Perangkat Lunak}

Pemodelan sistem digunakan untuk menentukan fungsifungsi yang dapat dilakukan oleh sistem pada rancang bangun aplikasi dengan menggunakan UML (Unified Modeling Language).

\section{E. Usecase Diagram}

Use case diagram menggambarkan fungsionalitas yang diharapkan dari sebuah sistem. Sebuah use case merepresentasikan sebuah interaksi antara aktor dengan sistem.

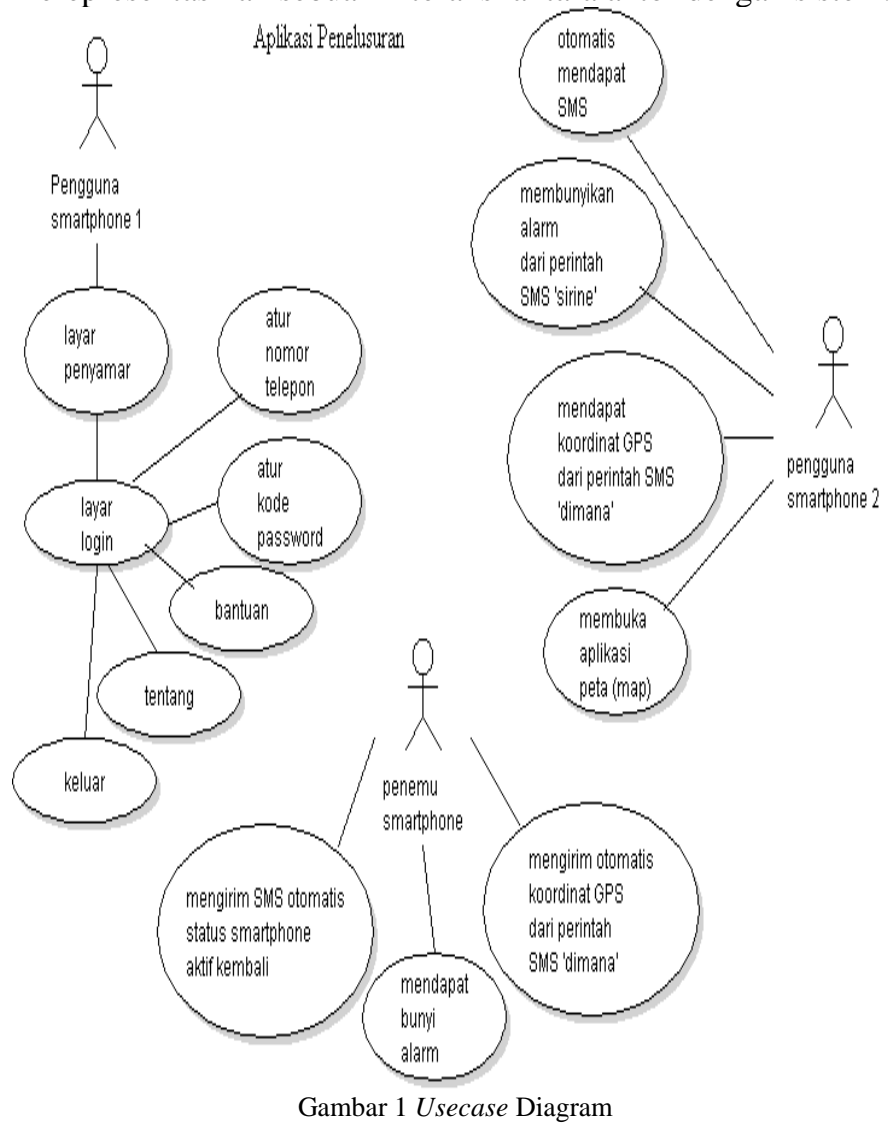

Gambar 1 terdiri dari aktor pengguna memiliki beberapa use case yaitu layar penyamaran, login, pengaturan nomor teman, pengaturan kode kunci password, bantuan, tentang. Sedangkan Aktor teman memiliki empat buah use case yaitu otomatis mengirim SMS saat diaktifkan kembali (reboot), membunyikan suara alarm, mendapatkan koordinat GPS, buka google map.

Use case akan terlihat dimana pengguna, memberikan perintah atau aksi dan respon apa yang akan diberikan oleh sistem kepada teman, setelah itu teman akan memberikan
Gambar 3 Activity Diagram pengguna dua
JTsiskom - 181

\section{F. Activity Diagram}

Activity Diagram menggambarkan berbagai alir aktivitas dalam sistem yang sedang dirancang, bagaimana masingmasing alir berawal, decision yang mungkin terjadi, dan bagaimana mereka berakhir. Activity Diagram juga dapat menggambarkan proses paralel yang mungkin terjadi pada beberapa eksekusi.

Sebuah aktivitas dapat direalisasikan oleh satu use case atau lebih. Aktivitas menggambarkan proses yang berjalan, sementara use case menggambarkan bagaimana aktor menggunakan sistem untuk melakukan aktivitas.

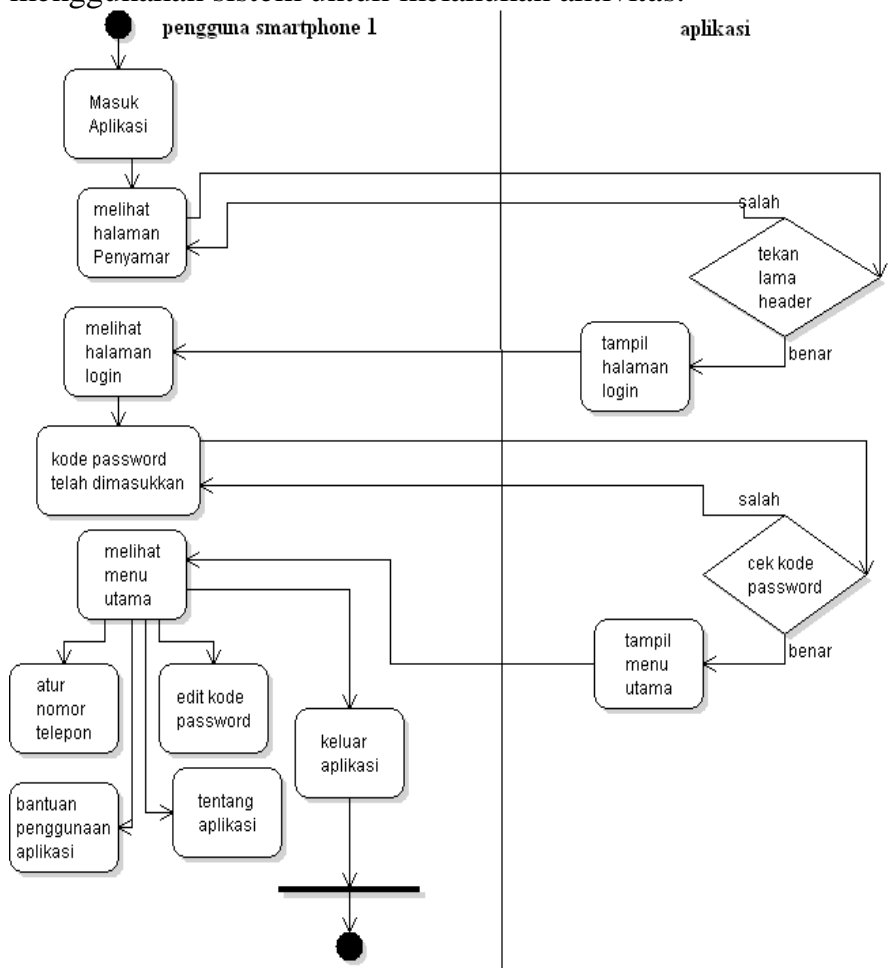

Gambar 2 Activity Diagram pengguna satu

Gambar 2 menjelaskan pengguna masuk aplikasi dan melihat halaman penyamaran, lalu menekan lama pada bagian header, jika tekan lama benar, maka akan menampilkan halaman login, dimana pengguna masuk kedalam aplikasi dan memasukkan kode kunci, kemudian sistem mengecek kode kunci apakah benar atau tidak. Jika benar, maka aplikasi akan masuk ke menu utama yakni atur nomor telepon, edit kode password, bantuan penggunaan aplikasi, tentang aplikasi, serta keluar aplikasi.

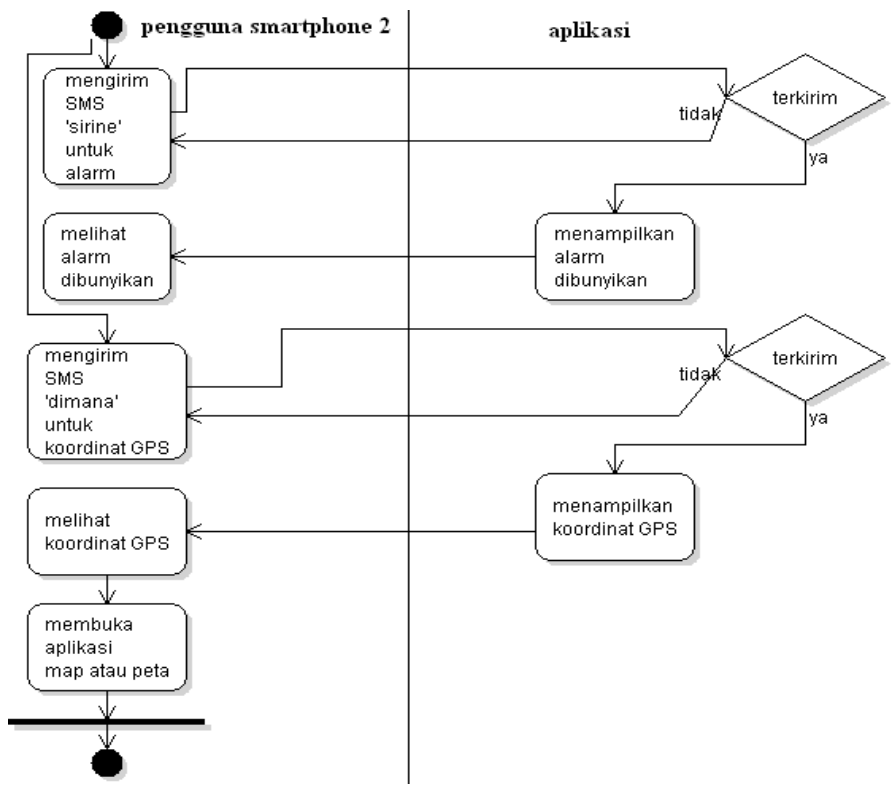

Gambar 3 Activity Diagram pengguna dua
JTsiskom - 181 
Gambar 3 menjelaskan pengguna mengirim SMS 'sirine' untuk membunyikan suara alarm, jika pesan terkirim, maka akan terlihat dan tampil alarm dibunyikan. Kemudian pengguna juga mengirim SMS 'dimana' untuk mendapat koordinat GPS, jika pesan terkirim, maka akan terlihat dan tampil koordinat, setelah itu bisa dibuka pada aplikasi map, seperti google maps.

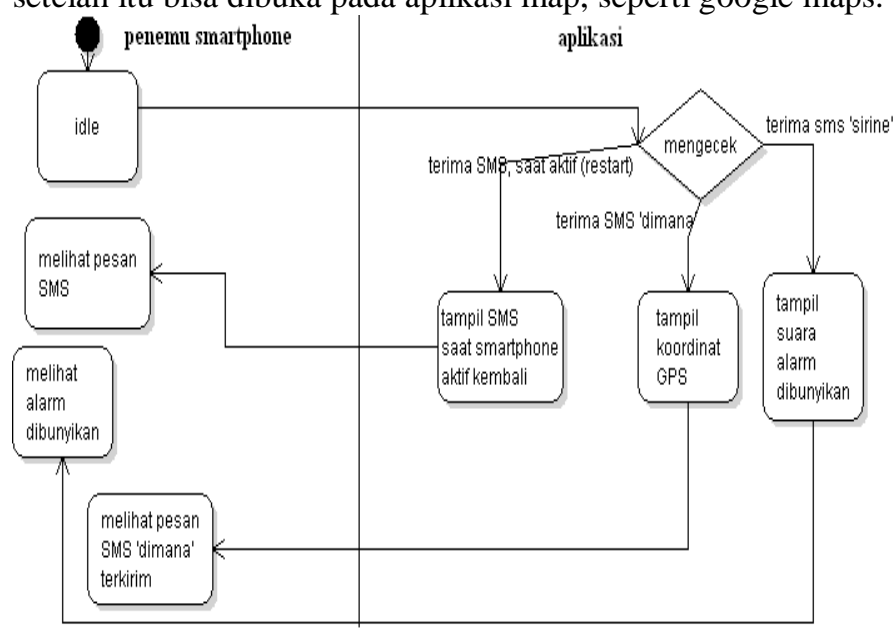

Gambar 4 Activity Diagram penemu smartphone

Gambar 4 menjelaskan bahwa penemu tidak sadar, jika perintah SMS telah dikirim secara otomatis, kalau smartphone mengalami pengaktifan kembali atau restart. setelah itu nomor telepon yang mengirim SMS pengaktifan, kirim SMS balik dengan perintah SMS 'sirine' 'dimana'. Kalau perintah SMS berhasil terkirim, maka perintah SMS 'sirine' untuk membunyikan alarm, sedangkan perintah SMS 'dimana untuk mendapatkan koordinat GPS, kemudian bisa membuka pada aplikasi map, seperti google maps.

\section{G. Class Diagram}

Class diagram merupakan struktur statis yang menggambarkan struktur dari suatu sistem dengan menunjukkan sistem kelas, atribut, operasi, dan hubungan antara objek-objek, sekaligus menawarkan layanan untuk memanipulasi keadaan tersebut (metode/fungsi). Tujuannya untuk menunjukkan hubungan, atau asosiasi, yang dimiliki suatu kelas dengan kelas yang lain.

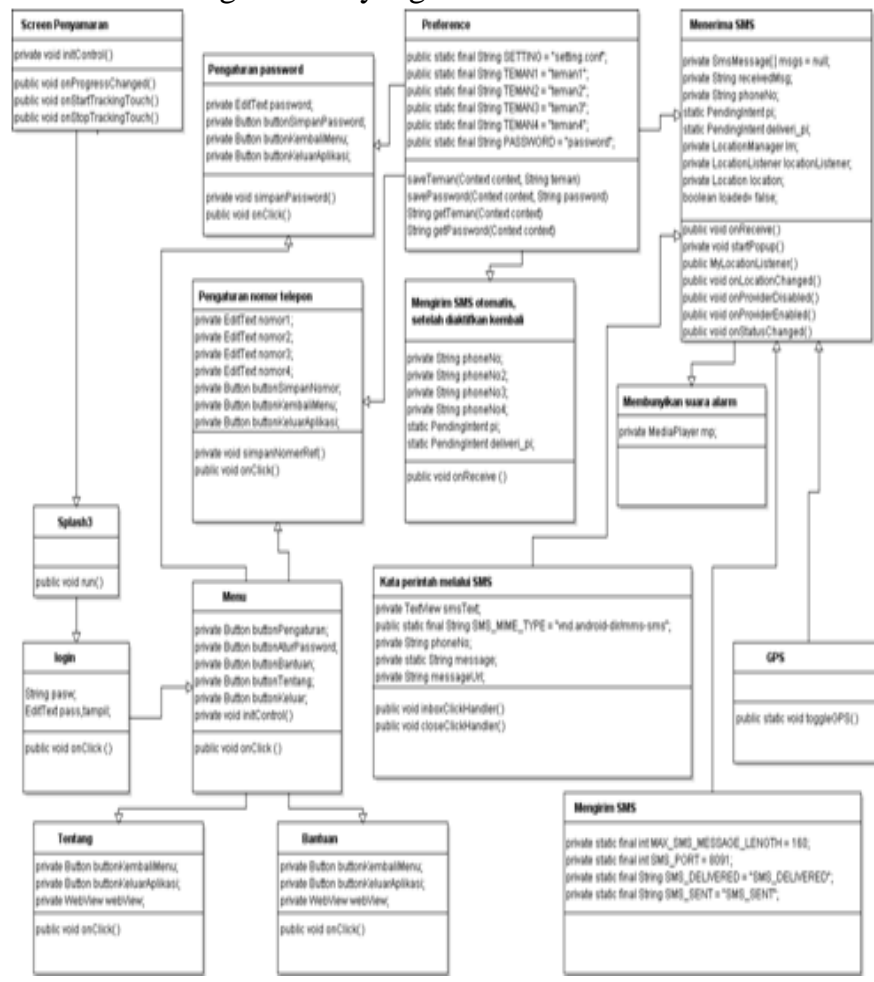

IV. ANALISA PEMBAHASAN

A. Aplikasi

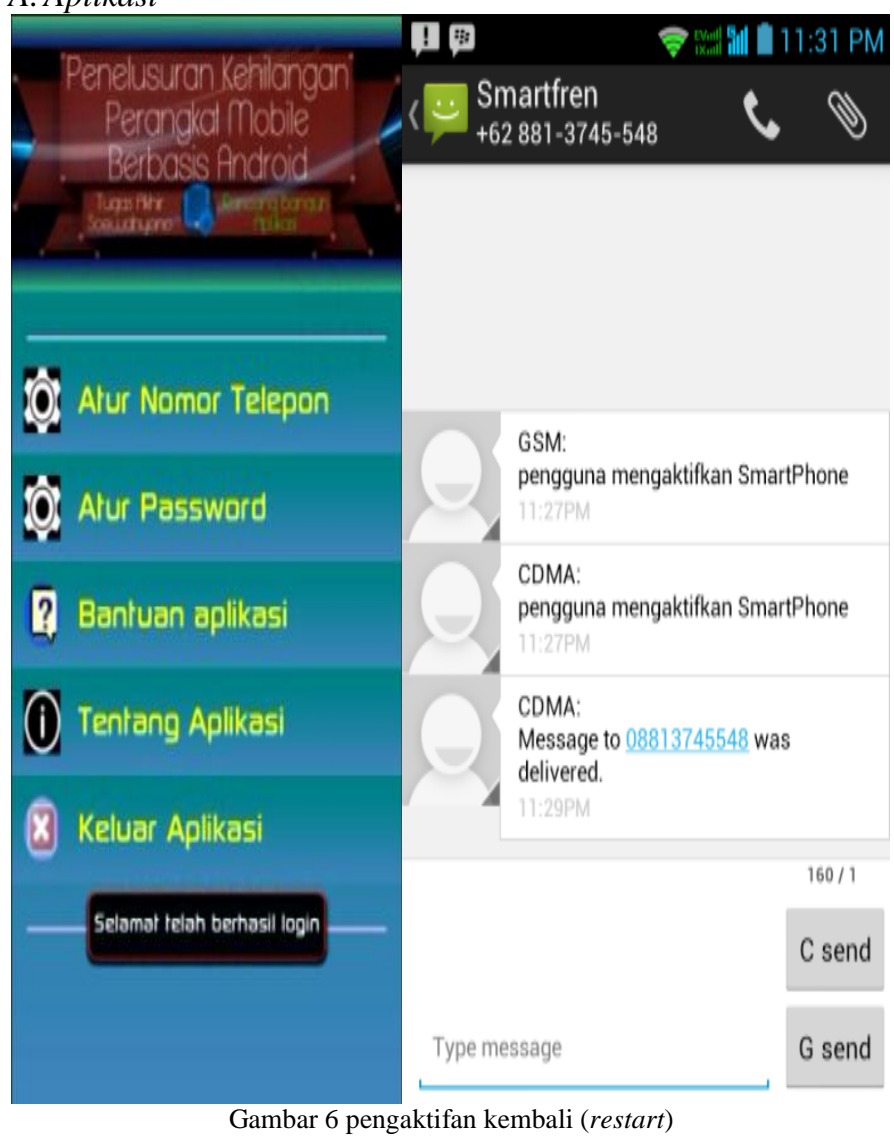

Gambar 6 menerangkan jika smartphone yang sudah memakai aplikasi penelusuran kehilangan, telah mengalami pengaktifan kembali (reboot), maka nomor telepon teman yang sudah terdaftar, akan menerima pesan SMS yaitu pengguna mengaktifkan smartphone.

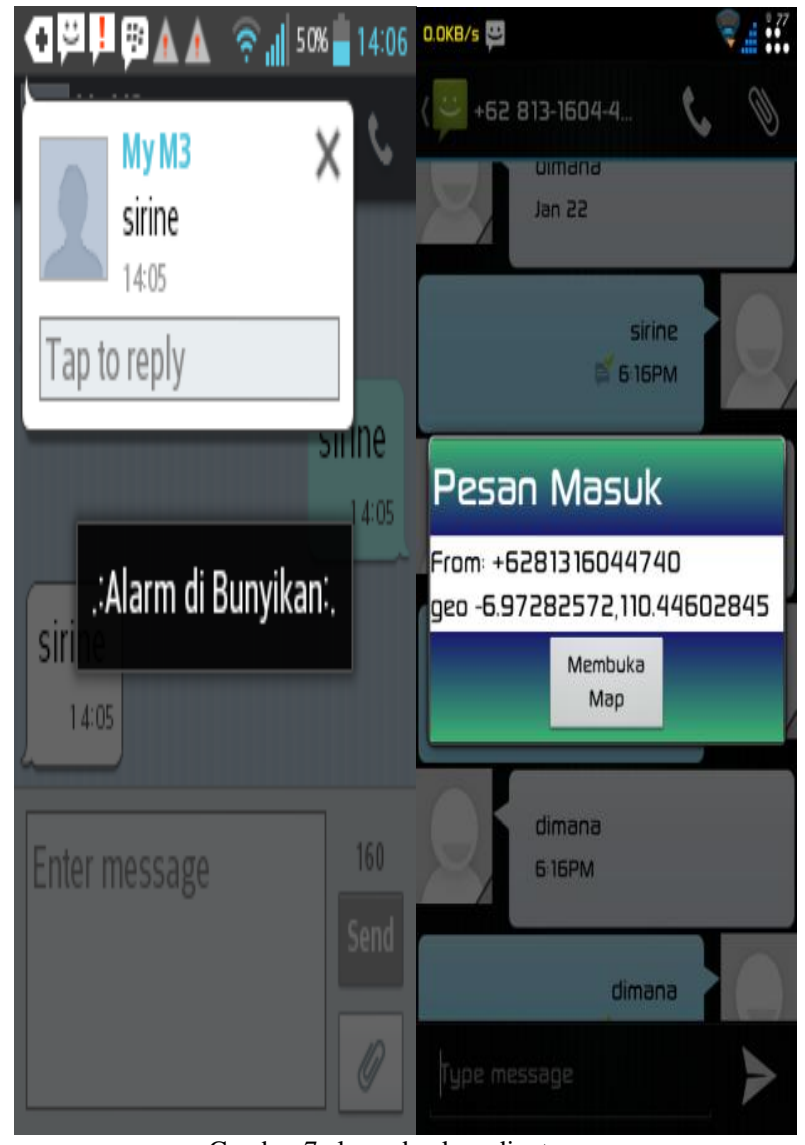

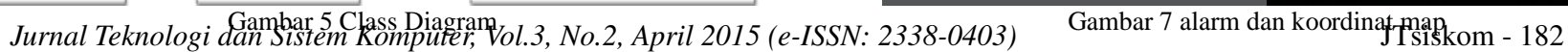


Gambar 7 menjelaskan perintah melalui SMS 'sirine', yang dikirim ke nomor teman yang sudah terdaftar, kalau pesan SMS telah terkirim, maka akan otomatis muncul bunyi suara alarm. Dan menerangkan perintah SMS 'dimana', yang dikirim ke nomor teman yang sudah terdaftar, kalau pesan SMS telah terkirim, akan menginformasikan posisi smartphone yang hilang, berupa koordinat lintang dan koordinat bujur. Serta terdapat tombol "Buka Map" yang berfungsi untuk menerjemahkan koordinat lintang dan bujur yang diterima ke dalam aplikasi map(google map)

Gambar 8 menunjukkan lokasi keberadaan smartphone yang hilang, yang berdasarkan koordinat lintang dan koordinat bujur. Lokasi keberadaan yang sudah ditemukan, akan ditandai dengan simbol marker sehingga memudahkan pengguna untuk mengetahui posisi lokasinya.

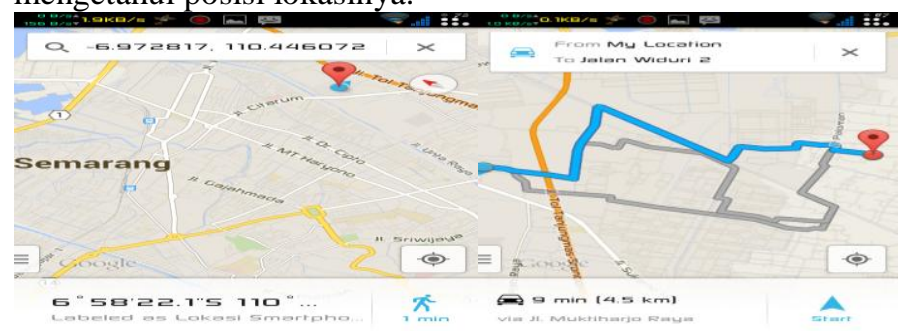

Gambar 8 lokasi keberadaan smartphone

\section{B. Pengujian perangkat lunak}

Dilakukan agar memastikan respon masukan yang menjalankan proses, dapat menghasilkan keluaran sesuai dengan rancangan. Serta untuk mencari kesalahan pemrograman, pengujian juga digunakan untuk melakukan verifikasi dan validasi hasil terhadap perancangan dan analisis.

Pengujian black box yang ditunjukan tabel 1, adanya pengujian identifikasi, serta pelaksanaan pengujian menu utama pada aplikasi.

Kasus uji aplikasi penelusuran kehilangan perangkat mobile berbasis android, ditunjukkan pada tabel 2 layar penyamar, tabel 3 halaman login, tabel 4 menu utama aplikasi.

TABEL I

PENGUJiAn BLACK BOX

\begin{tabular}{|c|c|c|c|c|c|}
\hline \multirow{2}{*}{$\begin{array}{c}\text { Kelas } \\
\text { Uji }\end{array}$} & \multirow{2}{*}{$\begin{array}{c}\text { Butir } \\
\text { Uji }\end{array}$} & \multicolumn{2}{|c|}{ Identifikasi } & \multirow{2}{*}{$\begin{array}{l}\text { Tingkat } \\
\text { Penguji } \\
\text { an }\end{array}$} & \multirow{2}{*}{$\begin{array}{c}\text { Jenis } \\
\text { Pengu } \\
\text { jian }\end{array}$} \\
\hline & & Sumber & Hasil & & \\
\hline $\begin{array}{l}\text { Layar } \\
\text { Penya } \\
\text { mar }\end{array}$ & $\begin{array}{l}\text { Menampil } \\
\text { kan tujuh } \\
\text { tombol } \\
\text { geser dan } \\
\text { tombol } \\
\text { tekan } \\
\text { lama pada } \\
\text { bagian } \\
\text { header }\end{array}$ & $\begin{array}{c}\text { Usecase } \\
1\end{array}$ & $\begin{array}{c}\text { Kasus } \\
\text { Uji } \\
1\end{array}$ & $\begin{array}{c}\text { Penguji } \\
\text { an } \\
\text { sistem }\end{array}$ & $\begin{array}{l}\text { Black } \\
\text { Box }\end{array}$ \\
\hline $\begin{array}{l}\text { Hala } \\
\text { man } \\
\text { login }\end{array}$ & $\begin{array}{l}\text { Menampil } \\
\text { kan } \\
\text { halaman } \\
\text { password } \\
\text { empat } \\
\text { digit } \\
\text { angka }\end{array}$ & $\begin{array}{c}\text { Usecase } \\
2\end{array}$ & $\begin{array}{c}\text { Kasus } \\
\text { Uji } \\
2\end{array}$ & $\begin{array}{l}\text { Penguji } \\
\text { an } \\
\text { sistem }\end{array}$ & $\begin{array}{l}\text { Black } \\
\text { Box }\end{array}$ \\
\hline $\begin{array}{l}\text { Hala } \\
\text { man } \\
\text { Menu } \\
\text { Utam } \\
\text { a }\end{array}$ & $\begin{array}{l}\text { Menampil } \\
\text { kan } \\
\text { beberapa } \\
\text { menu } \\
\text { yang ada } \\
\text { di aplikasi } \\
\text { terdiri dari }\end{array}$ & $\begin{array}{c}\text { Usecase } \\
3\end{array}$ & $\begin{array}{c}\text { Kasus } \\
\text { Uji } \\
3\end{array}$ & $\begin{array}{l}\text { Penguji } \\
\text { an } \\
\text { sistem }\end{array}$ & $\begin{array}{l}\text { Black } \\
\text { Box }\end{array}$ \\
\hline
\end{tabular}

\begin{tabular}{|l|l|l|l|l|}
\hline atur & & & & \\
nomor & & & \\
telepon, & & & \\
atur & password, & & & \\
bantuan & & & & \\
aplikasi, & & & \\
tentang & & & \\
aplikasi, & & & & \\
keluar & & & & \\
aplikasi & & & & \\
\hline
\end{tabular}

TABEL II

Kasus UJi APLIKASI PADA HALAMAN PENYAMAR

\begin{tabular}{|l|l|}
\hline Identifikasi & Kasus Uji \\
\hline Deskripsi & Layar penyamar \\
\hline $\begin{array}{l}\text { Prosedur } \\
\text { Pengujian }\end{array}$ & $\begin{array}{l}\text { Ada tujuh tombol geser dan tombol tekan } \\
\text { lama, untuk tombol tekan lama berfungsi } \\
\text { untuk melanjutkan ke halaman layar } \\
\text { berikutnya }\end{array}$ \\
\hline Masukan & $\begin{array}{l}\text { Menekan lama sekitar 2-3 detik pada bagian } \\
\text { judul }\end{array}$ \\
\hline $\begin{array}{l}\text { Keluaran } \\
\text { yang } \\
\text { diharapkan }\end{array}$ & $\begin{array}{l}\text { Selanjutnya sistem menampilkan halaman } \\
\text { login, jika telah menekan lama sekitar 2-3 } \\
\text { detik pada tombol bagian judul. } \\
\text { sedangkan jika melakukan tekan tombol } \\
\text { sebentar maupun beberapa kali tekan tombol, } \\
\text { maka tidak akan bisa menampilkan halaman } \\
\text { login. }\end{array}$ \\
\hline $\begin{array}{l}\text { Kriteria } \\
\text { Evaluasi } \\
\text { Hasil }\end{array}$ & $\begin{array}{l}\text { Memenuhi validasi, jika keluaran yang } \\
\text { diharapkan telah terpenuhi }\end{array}$ \\
\hline $\begin{array}{l}\text { Hasil yang } \\
\text { di dapat }\end{array}$ & $\begin{array}{l}\text { Dengan diberikan masukan sesuai rencana } \\
\text { pengujian, sistem telah dapat memberikan } \\
\text { keluaran (tampilan dan fungsi), sesuai yang } \\
\text { diharapkan }\end{array}$ \\
\hline Kesimpulan & Sukses \\
\hline
\end{tabular}

TABEL III

KASUS UJI APLIKASI PADA HALAMAN LOGIN

\begin{tabular}{|l|l|}
\hline Identifikasi & Kasus Uji 2 \\
\hline Deskripsi & Halaman login \\
\hline $\begin{array}{l}\text { Prosedur } \\
\text { Pengujian }\end{array}$ & $\begin{array}{l}\text { Memiliki kode kunci password yang terdapat } \\
\text { empat digit angka }\end{array}$ \\
\hline Masukan & $\begin{array}{l}\text { Kode kunci password awal '0000', atau } \\
\text { password yang diganti dengan empat digit } \\
\text { angka sesuai selera }\end{array}$ \\
\hline $\begin{array}{l}\text { Keluaran } \\
\text { yang } \\
\text { diharapkan }\end{array}$ & $\begin{array}{l}\text { Sistem akan menampilkan halaman } \\
\text { berikutnya, yaitu halaman splash screen, } \\
\text { selanjutnya akan menampilkan halaman menu } \\
\text { utama aplikasi. }\end{array}$ \\
\hline $\begin{array}{l}\text { Kriteria } \\
\text { Evaluasi } \\
\text { Hasil }\end{array}$ & $\begin{array}{l}\text { Memenuhi validasi, jika keluaran yang } \\
\text { diharapkan telah terpenuhi }\end{array}$ \\
\hline $\begin{array}{l}\text { Hasil yang di } \\
\text { dapat }\end{array}$ & $\begin{array}{l}\text { Dengan diberikan masukan sesuai rencana } \\
\text { pengujian, sistem telah dapat memberikan } \\
\text { keluaran (tampilan dan fungsi), sesuai yang } \\
\text { diharapkan }\end{array}$ \\
\hline Kesimpulan & Sukses \\
\hline
\end{tabular}

TABEL IV

KASUS UJi APLIKASI PADA MENU UTAMA

\begin{tabular}{|l|l|}
\hline Identifikasi & Kasus Uji \\
\hline Deskripsi & Halaman Menu Utama \\
\hline Prosedur & Mempunyai menu utama yang terdiri dari : \\
\hline
\end{tabular}




\begin{tabular}{|c|c|}
\hline Pengujian & $\begin{array}{l}\text { 1. atur nomor telepon } \\
\text { 2. atur password } \\
\text { 3. bantuan aplikasi } \\
\text { 4. tentang aplikasi } \\
\text { 5. keluar aplikasi }\end{array}$ \\
\hline Masukan & $\begin{array}{l}\text { Jika menekan salah satu tombol dari halaman } \\
\text { menu utama, seperti: } \\
\text { 1. Menekan tombol atur nomor telepon. } \\
\text { 2. Menekan tombol atur password. } \\
\text { 3. Menekan tombol bantuan aplikasi. } \\
\text { 4. Menekan tombol tentang aplikasi. } \\
\text { 5. Menekan tombol keluar aplikasi. }\end{array}$ \\
\hline $\begin{array}{l}\text { Keluaran } \\
\text { yang } \\
\text { diharapkan }\end{array}$ & $\begin{array}{l}\text { Sistem akan menampilkan halaman dari } \\
\text { tombol yang telah di tekan, seperti: } \\
\text { 1. Menekan tombol atur nomor telepon, yang } \\
\text { digunakan untuk memasukkan angka atau } \\
\text { nomor telepon teman yang hendak } \\
\text { disimpan. } \\
\text { 2. Menekan tombol atur password, pengguna } \\
\text { (user) juga bisa menggantinya dengan } \\
\text { empat digit angka sesuai selera. } \\
\text { 3. Menekan tombol bantuan aplikasi, yang } \\
\text { akan berfungsi bagaimana cara kerja } \\
\text { aplikasi penelusuran kehilangan } \\
\text { perangkat mobile. } \\
\text { 4. Menekan tombol tentang aplikasi, } \\
\text { menjelaskan informasi tentang aplikasi } \\
\text { penelusuran kehilangan perangkat mobile. } \\
\text { 5enekan tombol keluar aplikasi, jika akan } \\
\text { menutup aplikasi }\end{array}$ \\
\hline $\begin{array}{l}\text { Kriteria } \\
\text { Evaluasi } \\
\text { Hasil }\end{array}$ & $\begin{array}{l}\text { Memenuhi validasi, jika keluaran yang } \\
\text { diharapkan terpenuhi }\end{array}$ \\
\hline $\begin{array}{l}\text { Hasil yang } \\
\text { di dapat }\end{array}$ & $\begin{array}{l}\text { Dengan diberikan masukan sesuai rencana } \\
\text { pengujian, sistem telah dapat memberikan } \\
\text { keluaran (tampilan dan fungsi), sesuai yang } \\
\text { diharapkan }\end{array}$ \\
\hline Kesimpulan & Sukses \\
\hline
\end{tabular}

\section{KESIMPULAN DAN SARAN}

Pada bagian ini akan dijelaskan kesimpulan dan saran dari hasil penelitian dan pembahasan.

\section{A. Kesimpulan}

Berdasarkan hasil penelitian dan pembahasan, maka dapat diambil kesimpulan sebagai berikut :

1. Mengetahui posisi letak keberadaan smartphone yang hilang maupun lupa menaruhnya, dengan bantuan peta digital, seperti google maps.

2. Jika aplikasi penelusuran kehilangan perangkat mobile smartphone sudah terpasang, maka akan mengirim SMS secara otomatis saat smartphone mengalami pengaktifan kembali (reboot), jika nomor telepon teman sudah di daftarkan sebelumnya pada form isi nomor telepon, jadi pengguna (user) tidak perlu khawatir, kalau pihak pencuri atau tangan jahil telah mengganti nomor simcard pada smartphone yang hilang, karena pengguna atau teman akan mengetahuinya jika nomor kartu yang baru telah diaktifkan kembali oleh smartphone hilang.

3. Demi terjaganya keamanan aplikasi penelusuran kehilangan perangkat mobile dilengkapi layar penyamar dan kode kunci password, serta mendaftarkan empat nomor teman yang dapat menginformasikan keadaan smartphone yang hilang.

\section{B. Saran}

Terdapat beberapa saran dari hasil penelitian yaitu sebagai berikut :

1. Kemampuan sinyal dari perangkat mobile, mempengaruhi alur kerjanya aplikasi penelusuran kehilangan perangkat mobile dalam menentukan posisi koordinat.

2. Pengembangan selanjutnya, diharapkan aplikasi penelusuran kehilangan perangkat mobile, bisa dikendalikan dari jarak jauh, agar penemu tidak bisa mengakses data yang bersifat penting.

3. Aplikasi penelusuran masih memerlukan fitur tambahan berupa aplikasi maps, Google Maps yang digunakan untuk menelusuri posisi keberadaan koordinat lintang dan koordinat bujur dari keluaran perangkat GPS smartphone yang hilang.

\section{DAFTAR PUSTAKA}

[1]. Ableson, W.F., 2012. Android in Action, Shelter Island: Manning.

[2]. Adil, Ratna (2009). Sistem Informasi Via Sms Gateway Antara Pihak Kepolisian Dengan Pengemudi : Politeknik Elektronika Negeri Surabaya.

[3]. Cinar, O., 2012. Android Apps With Eclipse, Apress.

[4]. H, Nazruddin Safaat, Pemrograman Aplikasi Mobile Smartphone dan Tablet PC Berbasis Android, Informatika, Bandung, 2012.

[5]. Hans-Erik Eriksson dan Manus Penker. 1998. UML Toolkit

[6]. Hermawan, Stepasnus (2011). Mudah Membuat Aplikasi Android : Andi

[7]. Ir. Ono. W. Purbo, PhD, 1997. Membuat Aplikasi Untuk Android

[8]. Kendall, K.E., 2011. Systems Analysis And Design, New Jersey: Pearson.

[9]. Muhhamad Admiral, 2010. Aplikasi Pengingat Shalat dan Arah Kiblat Menggunakan Global Positioning System Berbasis Android, Tugas Akhir, Teknik Informatika Institut Teknologi Indonesia.

[10]. Nazruddin, S, Aplikasi Berbasis Android, Informatika. Bandung, 2013.

[11]. Nugraha, I.S., 2013. Perancangan Aplikasi Augmented Reality Untuk Pembelajaran Pengenalan Alat Musik Piano Berbasis Android. Tugas Akhir Teknik Sistem Komputer Undip.

[12]. Pressman, Roger. S, Ph.D. 2010. Software Engineering: A Practitioner Approach. New York: The McGraw-Hill Companies Inc.

[13]. Siahaan, R.R., 2013. Implementasi Sistem Informasi Geografis Daerah Pariwisata Kota Semarang Berbasis Android Dengan Global Positioning System (Gps). Tugas Akhir Teknik Sistem Komputer Undip.

[14]. Siregar, Ivan Michael, Membongkar Source Code Berbagai Aplikasi Android, Gava Media, Yogyakarta. 2011.

[15]. Yasin, V., Rekayasa Perangkat Lunak, Mitra Wacana Media, Jakarta, 